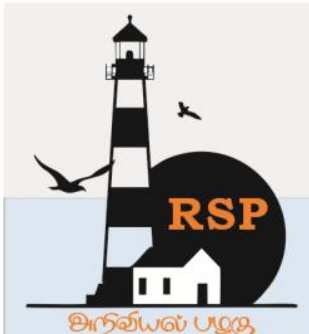

INTERNATIONAL RESEARCH JOURNAL ON ADVANCED SCIENCE HUB

-ISSN : $2582-437$
Open Access

RSP SCIENCE HUB

(The Hub of Research Ideas)

Available online at www.rspsciencehub.com

\title{
Calculation of State of Charge and State of Health of a Battery Management System in Electric Vehicle
}

Prof Rakshitha Ravi ${ }^{1}$, Dr Usha Surendra ${ }^{2}$

${ }^{1}$ RakshithaRavi, Department of ECE RV institute of technology and management, Bangalore, India

${ }^{2}$ Dr Usha Surendra ,Department of EEE,Christ (Deemed to be )University, Bangalore, India

rakshitha.r@res.christuniversity.in ${ }^{1}$

\section{Abstract}

In Present scenario Internal Combustion Engines [ICE] is overcome by Electric Vehicles [EV] due to advantages like reduction in carbon-di-oxide $\left[\mathrm{CO}_{2}\right]$ emission, cost. Advancement in electric vehicles are extensively going on and one such concept is Battery management system [BMS]in Battery Electric vehicle. In Battery Electric Vehicle there are many types of batteries and from the literature survey Lithium Ion Battery can be concluded to be suitable as it is advantageous in weight, cost, energy density and many aspects. The usage of Lithium-ion (Li-ion) batteries has increased significantly in recent years due to their long lifespan, high energy density, high power density, and environmental benefits. various internal and external faults can occur during the battery operation, leading to performance issues and potentially serious consequences, such as thermal runaway, fires, or explosion. In Battery electric vehicle Battery plays an important role. Battery may be overcharged or it may undergo faults. Hence a proper management system is required to control the Electric vehicle [EV] and it is called battery management system [BMS]. BMS has to be designed properly and major aspects to be taken care are State of Charge, State of Health, Cell balancing, Thermal heat dissipation, Temperature, Pressure.

Keywords-coulomb counting, state of charge, state of health

\section{Introduction}

In present scenario Internal Combustion Engine have been overcome by Electric Vehicles. To design an efficient electric vehicle many aspects, have to be considered. One such concept is Battery Management System. To design Battery Management System several concepts, have to be taken care like State of charge, State of Health, cell balancing method. The main function of the Battery Management System is to keep any single cell of the battery pack inside its safe operating area (SOA) by monitoring the following physical quantities: stack charge and discharge current, single cell voltage, and battery pack temperature. Based on these quantities, not only can the battery be operated safely, but also State of charge (SOC) and state of health (SOH) can be computed. For an effective battery management system, State of charge and Health plays an important role. State of charge has to be determined properly. If it is not determined and if the battery is overcharged then life of battery may reduce. Hence to determine state of charge algorithms have been developed Among the algorithms enhanced coulomb counting and Kalman filter are found out to be suitable depending on the type of system.

\section{Description of state of charge, state of health:}

In Present scenario Internal Combustion Engines [ICE] is overcome by Electric Vehicles [EV] due to advantages like reduction in carbon-di-oxide $\left[\mathrm{CO}_{2}\right]$ emission, cost. Advancement in 


\section{www.rspsciencehub.com}

electric vehicles are extensively going on and one such concept is Battery management system [BMS]in Battery Electric vehicle. In Battery Electric Vehicle there are many types of batteries and from the literature survey Lithium Ion Battery can be concluded to be suitable as it is advantageous in weight, cost, energy density and many aspects. The usage of Lithium-ion (Li-ion) batteries has increased significantly in recent years due to their long lifespan, high energy density, high power density, and environmental benefits. various internal and external faults can occur during the battery operation, leading to performance issues and potentially serious consequences, such as thermal runaway, fires, or explosion. In Battery electric vehicle Battery plays an important role. Battery may be overcharged or it may undergo faults. Hence a proper management system is required to control the Electric vehicle [EV] and it is called battery management system [BMS]. BMS has to be designed properly and major aspects to be taken care are State of Charge, State of Health, Cell balancing, Thermal heat dissipation, Temperature, Pressure. State of charge and health has to be given to the user for proper functioning of Electric Vehicle. In Electric Vehicle fuel cost and maintenance cost is reduced. Hence it proves to be more advantageous. Electric vehicle is advantageous as it reduces $\mathrm{CO}_{2}$ emission compared to internal combustion engine.

\section{Methodology}

The book-keeping methods also known as Coulomb-counting consist of a temporal integrating of the battery current during charge and discharge. The accuracy of book-keeping methods is strongly dependent on the precision of current sensors. These non-model-based methods may accumulate errors caused by measurements, possible embedded noise and an inaccurate initial SOC. Coulomb-counting based algorithm are often used as a core technology for battery SOC estimation in BMS. They express the SOC as the ratio of available capacity to the nominal one. The remaining capacity in a battery can be calculated by measuring the current flow rate (charging/discharging) and integrating it over the time interval $\Delta \tau$. Coulomb-counting is only based on direct measurement, so it is not hard to implement and gives enough precision of the SOC estimation in multimedia applications.
Volume 02 Issue 08 August 2020

It has always been a big concern to estimate the SOC for energy storage devices. The estimation accuracy of SOC does not only give information about the remaining useful capacity, but also indicates the charge and discharge strategies, which have a significant impact on the battery. Thus, a Liion battery may have different capacities due to aging, ambient temperature and self-discharge effects. Several methods for estimating SOC have been introduced in the literature. These non-modelbased methods may accumulate errors caused by measurements, possible embedded noise and an inaccurate initial SOC.

Table 1. Review of SOC estimation methods

\begin{tabular}{|c|c|}
\hline SOC estimation method & Characteristics \\
\hline $\begin{array}{l}\text { Electrochemical } \\
\text { - Impedance spectroscopy [15] }\end{array}$ & $\begin{array}{l}\text { - High accuracy } \\
\text { - Time consuming } \\
\text { - Hard to implement }\end{array}$ \\
\hline $\begin{array}{l}\text { Model-Based } \\
\text { - Kalman filter, extended Kalman } \\
\text { filter [18,25,26] } \\
\text { - Lunenberger observer [21] } \\
\text { - Proportional integral observer } \\
\text { [23] } \\
\text { - Sliding mode observer }[12,22]\end{array}$ & $\begin{array}{l}\text { - Good precision } \\
\text { - Accuracy depends on } \\
\text { the precision of the } \\
\text { battery model. } \\
\text { - Not easy to implement }\end{array}$ \\
\hline $\begin{array}{l}\text { Data-oriented } \\
\text { - Neural Network [13] } \\
\text { - Fuzzy Logic [14] } \\
\text { - SVM [27] }\end{array}$ & $\begin{array}{l}\text { - High accuracy } \\
\text { - Hard to implement } \\
\text { - Accuracy depends on } \\
\text { the training data }\end{array}$ \\
\hline $\begin{array}{l}\text { Book-keeping } \\
\text { - Coulomb-counting }[7,8]\end{array}$ & $\begin{array}{l}\text { - Average precision } \\
\text { - Simple to implement } \\
\text { - Cumulative errors } \\
\text { - Accuracy depends on } \\
\text { sensors measurement }\end{array}$ \\
\hline
\end{tabular}

\section{Conclusion:}

Electric vehicles are trending nowadays compared to internal combustion engine because of its advantages and less limitations. Global warming is effective with electric vehicles because of no emissions of gases. Limitations are the installed charging stations are not able to meet the increasing charging demand of Electric Vehicles. So if that is overcome then effectively electric cars can be into effect.

\section{References:}

[1].Wu, C.; Zhu, C.; Ge, Y.; Zhao, Y. A Review on Fault Mechanism and Diagnosis 
Approach for Li-Ion Batteries. J. Nanomater. 2018, 1-9. [CrossRef]

[2].Liu, Z.; Ahmed, Q.; Zhang, J.; Rizzoni, G.; $\mathrm{He}, \mathrm{H}$. Structural analysis based sensors fault detection and isolation of cylindrical lithium-ion batteries in automotive applications. Control Eng. Pract. 2016, 52, 46-58. [CrossRef]

[3].Liu, K.; Liu, Y.; Lin, D.; Pei, A.; Cui, Y. Materials for lithium-ion battery safety. Sci. Adv. 2018, 4, eaas9820. [CrossRef] [PubMed]

[4].Kong, L.; Li, C.; Jiang, J.; Pecht, M. Li-Ion Battery Fire Hazards and Safety Strategies. Energies 2018, 11, 2191. [CrossRef]

[5].Wei,J.;Dong,G.;Chen,Z.Modelbasedfaultdi agnosisofLithiumionbatteryusingstrongtrac ki ngExtended Kalman Filter. Energy Procedia 2019, 158, 2500-2505. [CrossRef] 